\title{
Entre el ardid y la sobreinterpretación. El test de comprensión lectora como género discursivo'
}

\author{
Between Trick and Overinterpretation. \\ The Reading Comprehension Test as Speech Genre \\ FACUNDO NIETO \\ Universidad Nacional de General Sarmiento \\ Argentina \\ fnieto@ungs.edu.ar
}

(Recibido o9-O3-2OI4; aceptado $07-07-2014)$

Resumen. Nuestro trabajo se propone analizar algunos rasgos del formato típico de los exámenes de comprensión lectora difundidos por la Dirección Nacional de Información y Evaluación de la Calidad Educativa (DiNIECE), unidad del Ministerio de Educación de la Nación Argentina que tiene a su cargo las tareas de planificar e implementar los Operativos Nacionales de Evaluación (ONE) y de administrar los exámenes internacionales PISA.

El análisis se ha realizado desde dos perspectivas teóricas. La primera, centrada en el texto, permite concebir este tipo de examen como género discursivo, es decir, como un tipo relativamente estable de enunciados caracterizado por una temática, una estructura y un estilo determinados (Bajtín, 1982 [1978]); en particular, consideramos su estructura en términos de discurso instruccional (Silvestri, 1995). La segunda perspectiva, centrada en el receptor-alumno, adopta conceptualizaciones semióticas que permiten pensar la "sobreinterpretación” (Eco, 1992) como modalidad particular de lectura.

Palabras clave: Evaluación de la educación; aptitud para la lectura; prueba de lectura; enseñanza secundaria ; alfabetización funcional.
Abstract. This article proposes to analyze a few characteristics of the typical structure of the reading comprehension tests published by the National Direction of Information and Evaluation of Educational Quality, an agency belonging to the Ministry of Education of the Argentine Republic and responsible for the planning and implementing of the National and the International Programs for Students Assessment.

The analysis was made from two theoretical perspectives. The first one, focused on the text, allows us to consider this type of test as a speech genre, that is, a relatively stable type of utterances with specific thematic content, style and compositional structure (Bajtin, 1982 [1978]); its compositional structure was considered as a type of instructional speech (Silvestri, 1995). The second perspective, focused on the addressee-student, consists of some semiotic concepts which allow us to consider the “overinterpretation" (Eco, 1992) as a particular way of reading.

Keywords: Educational evaluation; reading ability; reading tests; secondary education; functional literacy.

\footnotetext{
${ }^{\text {I }}$ Para citar este artículo: Nieto, Facundo (2OI4). Entre el ardid y la sobreinterpretación. El test de comprensión lectora como género discursivo. Alabe 10. [www.revistaalabe.com] 
La Dirección Nacional de Información y Evaluación de la Calidad Educativa (DiNIECE), unidad perteneciente al Ministerio de Educación de la Nación, tiene a su cargo las tareas de planificar e implementar en la República Argentina los Operativos Nacionales de Evaluación (ONE) ${ }^{2}$ y de administrar los exámenes internacionales PISA ${ }^{3}$ y SERCE 4 . Pese a sus diferencias, los tres tipos de exámenes coinciden en evaluar, entre otras áreas disciplinares, la comprensión lectora en los alumnos de todo el país. Con anterioridad a la implementación de un operativo de evaluación, la DiNIECE suele distribuir entre los docentes una serie de materiales destinados a su capacitación, y luego de procesados los datos obtenidos en los exámenes produce dos tipos de publicaciones: “informes de resultados" y "recomendaciones metodológicas".

La amplia difusión de estos materiales ha permitido conocer $-\mathrm{y}$ aun volver previsible- un formato recurrente de instrumento de evaluación de la comprensión lectora. Se trata de un examen compuesto por un texto (o más de uno) relativamente breve y por ejercicios consistentes en actividades de selección múltiple (una consigna es seguida por cuatro opciones de las cuales solo una es correcta) y unas pocas actividades de "respuestas abiertas breves" relativas al texto proporcionado para su lectura.

Toda vez que informan acerca de los operativos de evaluación, tanto los “informes" como las "recomendaciones" buscan persuadir a los destinatarios acerca de su neutralidad valorativa en lo que respecta al procesamiento de los resultados y, por este motivo, tratan de suprimir cualquier elemento que conlleve el riesgo de evidenciar intersticios de subjetividad. Un claro ejemplo de este intento se encuentra en las precauciones que las autoras de los materiales ${ }^{5}$ dicen adoptar en la instancia de corrección de las pruebas de los alumnos. En lo que respecta a las actividades cerradas, la opción múltiple constituiría la muestra más acabada de objetividad: no habría tarea menos sujeta a ambigüedades que aquella que puede corregirse de manera mecánica, sin intervención humana ${ }^{6}$. El proble-

\footnotetext{
${ }^{2}$ Los ONE se realizan periódicamente desde ig93 en las veinticuatro jurisdicciones del país. Las pruebas se aplican tanto en alumnos de la educación primaria (de tercero y de sexto grado) como en alumnos de la educación secundaria; en este último nivel se evalúan alumnos de segundo o tercer año y del último año.

${ }^{3}$ La sigla corresponde al Programa Internacional para la Evaluación de los Estudiantes, implementado por la Organización para la Cooperación y el Desarrollo Económico (OCDE), en el marco del cual se aplican exámenes trienales en las áreas de Lectura, Matemática y Ciencias en alumnos de alrededor de I5 años de edad. Los alumnos argentinos han sido evaluados por PISA en cuatro oportunidades: 2OOI, 2006, 2009 y 2012 (en 2003 Argentina no participó del programa).

${ }^{4}$ Se trata del Segundo Estudio Regional Comparativo y Explicativo (SERCE), organizado por el Laboratorio Latinoamericano de Evaluación de la Calidad de la Educación (LLECE) y la Oficina Regional de Educación de la UNESCO para América Latina y el Caribe (OREALC-UNESCO). El SERCE se implementó en el año 20o6; a diferencia de PISA, que se aboca a la evaluación de alumnos de la educación secundaria en tres áreas, en el marco del SERCE se aplicaron exámenes en alumnos de tercero y sexto año de la educación primaria (de alrededor de 8 y II años de edad, respectivamente) y en cuatro áreas: Lectura, Escritura, Matemática y Ciencias Naturales.

5 El Equipo autoral de Lengua de la DiNIECE está compuesto por las profesoras Beba Salinas, Graciela Piantanida y Graciela Fernández y las licenciadas Andrea Baronzini y Carmen de la Linde. Para este trabajo hemos consultado las recomendaciones metodológicas para el profesorado de secundaria correspondientes a los ONE 2O05, 2007/2008 y 2OIO, y al “Programa de Capacitación y Sensibilización” previo al operativo PISA de 20 2.

${ }^{6}$ El informe sobre los exámenes SERCE, que solo presentan ítems de opción múltiple, destaca así la objetividad de este tipo de actividades: “....si bien las preguntas de selección no permiten evaluar los sucesivos procesos mentales que los estudiantes desarrollan al responder, sí permiten evaluar errores comunes de forma economica (las respuestas pueden captarse mediante un lector óptico) y objetiva (no exigen el acuerdo posterior de correctores humanos)" (Atorresi \& al, 2009: 30).
} 
ma podría presentarse en la corrección de las consignas de respuesta abierta, pero los organizadores de los ONE declaran haber contemplado adecuadamente esta posibilidad:

\begin{abstract}
A diferencia de las actividades de opción múltiple que se corrigen mecánicamente, la corrección de los ítems abiertos debe realizarse manualmente.

Con el objetivo de lograr que la corrección de las actividades abiertas fuera completamente objetiva, se elaboraron grillas o guías de corrección en las que se explicitó el desempeño evaluado en la actividad, la tipificación de las respuestas en correctas, parcialmente correctas, incorrectas y en blanco, la descripción de la información contenida en cada tipo de respuesta y ejemplos tomados de estudiantes que habían participado en una muestra previa a la administración de la prueba ONE.

Con dichas grillas y la digitalización de las respuestas manuscritas de los alumnos, las actividades abiertas fueron corregidas en línea por docentes de varias provincias (Ministerio de Educación de la Nación, 2OIO: 9, cursivas nuestras).
\end{abstract}

No obstante, pese a estos y otros recaudos, la subjetividad no puede ocluirse cuando se trata de interpretar textos, es decir, cuando aquello que se evalúa es, en última instancia, producción de sentidos. Ni aun los discursos más rigurosos o "cientificistas" sobre la lectura avalan posiciones optimistas sobre la objetividad interpretativa: la propia Psicolingüística ha rechazado las concepciones objetivistas y lógico-formales de inferencia y acentúa los aportes de la subjetividad:

\begin{abstract}
El proceso de inferencia llevado a cabo por el lector/oyente alberga mecanismos mentales que no tienen necesariamente relación con los principios descritos por la lógica formal tradicional, es decir, formalizaciones silogísticas que se rigen por la aplicación de reglas sintácticas de inferencia. En efecto, creemos que el razonamiento humano no es, como muchos sostienen, correspondiente con la lógica deductiva [...]. De este modo, las inferencias realizadas durante (on-line) y después (off-line) del proceso de comprensión están preferentemente sustentadas en información que el lector/oyente aporta desde sus conocimientos previos y pueden denominarse inferencias basadas en el conocimiento previo. Por ello, desde el punto de vista del observador, muchas veces resulta difícil predecir con certeza el origen de una determinada inferencia, pues no parece posible conocer toda(s) la(s) proposición(es) considerada(s) por el sujeto comprendedor en el momento de su razonamiento (Parodi, 2005: 51-2).
\end{abstract}

Entonces, frente al problema de la objetividad teórico-metodológica creemos necesario formular dos observaciones. En primer lugar, el rigor técnico no garantiza objetividad en la evaluación de la comprensión lectora; efectivamente, en no pocas consignas que se presentan en los exámenes resulta posible observar una carga importante de subjetividad por parte de quienes las han diseñado. En segundo lugar, aun cuando los recaudos teóricos y técnicos permitan definir con absoluta objetividad los contenidos, las capacidades, los niveles de desempeño y los criterios de corrección, no parece necesariamente productiva la aplicación estricta de criterios preestablecidos en la corrección de los trabajos de los alumnos o, al menos, en el análisis de sus respuestas. Los modos de leer de los alumnos podrían comprenderse mejor si no se aplicaran taxativamente "grillas" o "guías 
de corrección" que a priori deslindan lo correcto de lo incorrecto. Por el contrario, creemos que podrían comprenderse mejor si se concibiera el examen de comprensión lectora como un género discursivo.

Concebir el examen de lectura como género discursivo (Bajtín, I982 [ı978]) implica considerar que el texto cuya comprensión se evalúa - una noticia, un artículo de opinión o un cuento- pierde en gran medida las características genéricas que poseía antes de su inclusión en el contexto del test. El texto es recontextualizado en el examen: al ser extraído de su ámbito de circulación original y al quedar subsumido en una prueba, deja de ser una noticia, una nota de opinión o un cuento, para convertirse en otra clase textual: un texto de examen.

En la situación de evaluación, el alumno-destinatario está sometido no solo a la lectura del texto en cuestión, sino también a la lectura de aquello que las consignas solicitan. Podría afirmarse entonces que las consignas son enunciados que hacen del texto otro texto diferente. Las estrategias cognitivas que un lector pone en práctica para la lectura del texto de examen, entonces, no son las mismas que aquellas que pondría en práctica si el mismo texto se leyera por fuera de la situación de examen, es decir, sin consignas que condicionaran su lectura. En efecto, en el marco de un examen, el lector está sujeto a dos eventualidades inherentes al género del test de comprensión lectora: la posibilidad del ardid y el riesgo de sobreinterpretar.

\section{Los ardides del destinador-evaluador}

La consigna de comprensión lectora presenta algunas similitudes significativas con otro género discursivo: el acertijo. Pese a sus notables diferencias (entre otras, el acertijo es un pasatiempo y, por lo tanto, no tiene consecuencias sobre el estatuto institucional del receptor), examen y acertijo se asemejan en dos puntos.

En primer lugar, en ambos predomina una secuencia textual instruccional: se trata de un conjunto de enunciados directivos, es decir, de un "discurso orientado a la ejecución práctica de acciones" (Silvestri, I995: I6) cuyo propósito consiste en lograr que el interlocutor ejecute una acción determinada y en los que el emisor manifiesta una autoridad basada en el poder o en el saber de los que el receptor carece (en el examen, la comunicación se produce entre un emisor-experto y un receptor-alumno); esta es la razón por la cual el acto ilocucionario propio de la situación comunicativa instruccional es la orden?

En segundo lugar, el acertijo y la consigna de examen comparten un rasgo que los diferencia de la mayor parte de los discursos instruccionales tales como reglamentos, instrucciones de uso, recetas de cocina, etc. En estos últimos,

\footnotetext{
7 "La formulación habitual de las consignas instruccionales adopta el imperativo o el infinitivo, lo que indica una clara situación de directividad que no necesita atenuar la orden por medio de modalizaciones. [...] Otra forma habitual de la consigna es la pregunta instruccional” (Silvestri, I995: 3O-I).
} 
es muy alta la cantidad de información que [el receptor] necesita para construir su representación semántica y para traducirla en un eficaz pasaje a la acción. Esta circunstancia genera el alto grado de explicitación del discurso instruccional (ibid.: 26-7, cursivas de la autora).

Por el contrario, como el acertijo y la consigna demandan un saber, las formulaciones del emisor-experto procuran un bajo nivel de explicitación. La consigna contiene, por un lado, la menor cantidad de información posible y, por otro lado, al menos en el caso de las consignas de opción múltiple, opciones incorrectas que técnicamente se denominan "distractores" ${ }^{\text {. }}$. Dicho de otro modo, tanto las consignas de examen de comprensión lectora como el acertijo esconden "una pequeña trampa”: el receptor-alumno debe descubrir cierta "argucia" o "ardid" que el emisor-experto ha introducido en la actividad para que la respuesta no resulte evidente.

Para ilustrar la analogía, tomemos un acertijo sencillo: "Si un hombre tarda media hora en cavar un pozo, ¿cuánto tardará ese hombre en cavar medio pozo?”. Si se enuncia la respuesta más evidente, que se obtiene a través de un simple cálculo matemático (quince minutos), se incurre en el error, dado que el género del acertijo presenta el ardid de rechazar la respuesta inmediatamente más obvia9; el ardid consiste en preguntar por la tarea de "cavar medio pozo" en lugar de preguntar por el tiempo empleado en cavar la mitad del pozo.

Tomemos ahora un ejemplo de una consigna en la que se produce un ardid similar, propuesta para el siguiente texto:

\section{EDIFICIOS ALTOS}

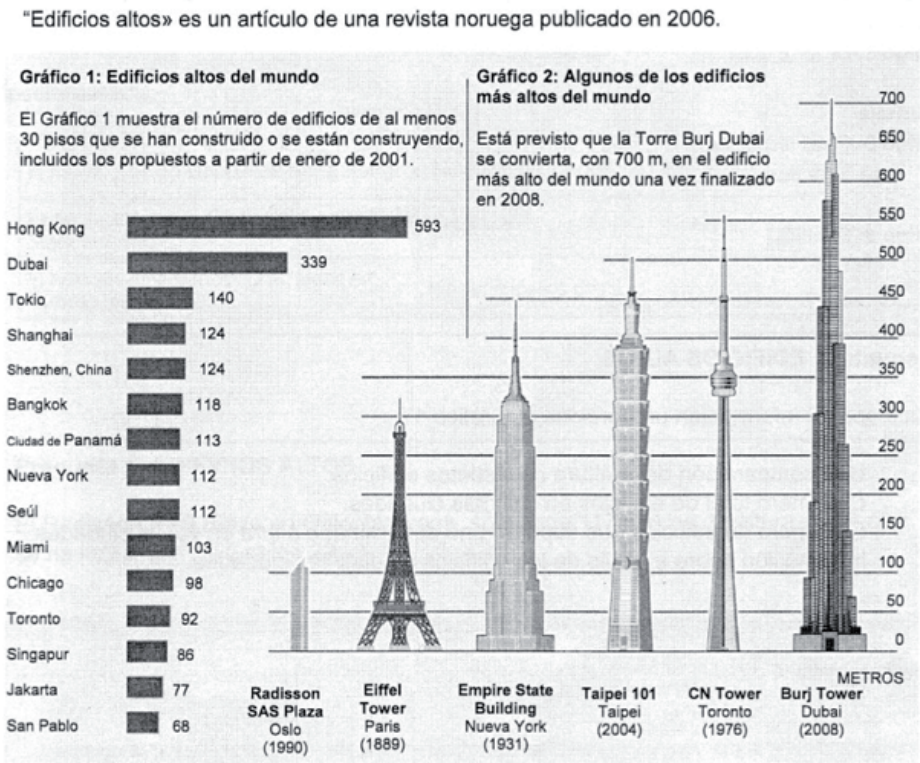

(Ministerio de Educación de la Nación, 2OI2: 37)

\footnotetext{
${ }^{8}$ Así se los denomina en los Aportes para la enseñanza de la Lectura (Atorresi \& al, 20o9) elaborados a partir de los exámenes SERCE. Se aclara también allí que "en muchos casos [los distractores] deben ser sutiles, pero nunca tanto como para que la respuesta correcta no pueda ser reconocida por un porcentaje significativo de estudiantes" (ibíd:: 29).

${ }^{9}$ En efecto, la respuesta del acertijo es: “Los medios pozos no existen, siempre es un pozo" (http://www.acertijos.net).
} 
En relación con este texto, una de las consignas solicita la siguiente información:

El Radisson SAS Plaza en Oslo, Noruega, sólo tiene II7 metros de altura. ¿Por qué se ha incluido en el Gráfico 2 ?

(ibid:: 39)

A continuación, el material presenta los criterios de corrección que determinan la distribución del puntaje en tres categorías: "puntaje completo", "puntaje parcial" o "sin puntaje”. Según determinan los criterios, una respuesta quedará sin puntaje si el alumno "proporciona una respuesta insuficiente o vaga" (ibíd.: 40, subrayado en el original). Con el fin de ilustrar este tipo de respuesta "insuficiente", es decir, incorrecta, el material proporciona como ejemplos, entre otros, los siguientes enunciados posibles:

- II 7 metros siguen siendo mucha altura.

- Porque es uno de los edificios más altos del mundo.

(ibíd:: 40)

Tales respuestas, explica el material, deben considerarse "sin puntaje". De modo que ante la pregunta sobre por qué el edificio Radisson SAS Plaza de Oslo fue incluido en un gráfico sobre "algunos de los edificios más altos del mundo" (tal como reza el epígrafe del gráfico), la respuesta más obvia ("Porque es uno de los edificios más altos del mundo") será considerada incorrecta por el destinador-evaluador.

Aquí es donde se observa la presencia del ardid. Ante la pregunta por la inclusión de un determinado edificio en un gráfico sobre "edificios más altos del mundo", se considerará incorrecto que el destinatario explique que ese edificio ha sido incluido en el gráfico por ser uno de los más altos del mundo. Según las autoras del material, la respuesta correcta, la que sí reunirá el puntaje completo, es aquella que "se refiere al hecho de que el artículo es de una revista noruega o a que los lectores van a ser probablemente noruegos" (ibíd.: 40, subrayado en el original), dado que un edificio conocido funcionaría como referencia inmediata para el lector noruego de la revista donde el texto fue publicado $^{\text {Iо }}$. El destinador exige así una respuesta que, en rigor, no forma parte del texto evaluado, sino que se encuentra por fuera de esos gráficos: quien informa acerca de la procedencia del artículo no es el autor del artículo, sino el destinador del examen.

Un segundo ejemplo de ardid puede observarse en la siguiente actividad, incluida en el ONE 2005, referida al cuento "El plan malévolo", de O. Henry, protagonizado por una mujer de nombre Marta:

\footnotetext{
${ }^{\text {Io }}$ En este sentido podría afirmarse que algunas consignas trabajan en el nivel inferencial de lo que Teum van Dijk y Walter Kintsch han denominado la "probabilidad mínima" (faintest possibility): "Lexical inferences range from certainty (John killed Sue - Sue is dead) to plausibility (She punched John - She used her fist) to the faintest possibility (Sue is ill - with peritonites)" (van Dijk \& Kintsch, I983: 49, cursivas de los autores).
} 
Además de aparecer en los diálogos, el punto de vista de la señora Marta aparece en otras partes del texto. Copiá alguna frase del texto (que no sea parte de los diálogos, precedidos de guión) en la que se muestre lo que piensa la señora Marta.

(Ministerio de Educación de la Nación, 2008: II)

Un alumno, cuya respuesta es considerada correcta, transcribe el siguiente fragmento:

\section{$4 \quad$ Además de aparecer en los diálogos, el punto de vista de la señora Marta aparece en otras partes del texto. Copiá alguna frase del texto (que no sea parte de los diálogos, precedidos de guión) en la que se muestre lo que piensa la señora Marta.}

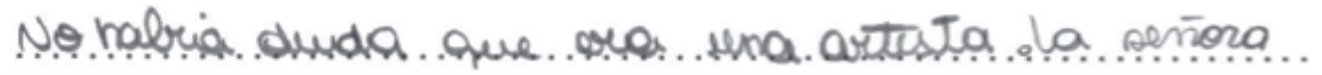

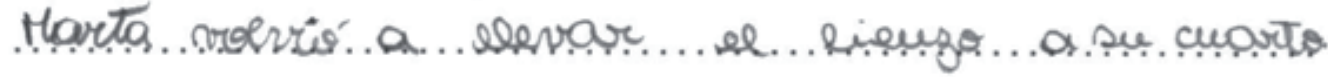

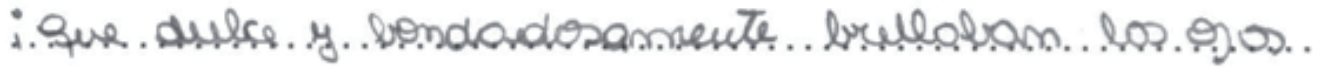

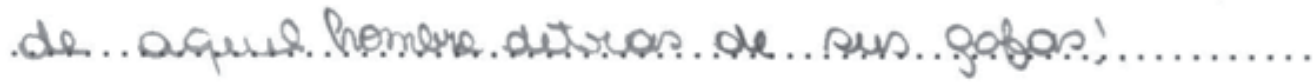

No había duda de que era una [un] artista. La señora Marta volvió a llevar el lienzo a su cuarto ;que dulce y bondadosamente brillaban los ojos de aquel hombre detrás de sus gafas!

(ibíd.: II)

Como señalan las autoras, la respuesta es considerada correcta dado que el alumno ha transcripto un fragmento del cuento en el que se observa el uso del discurso (o estilo) indirecto libre. El alumno logró deducir que, pese a que es el narrador quien dice "No había duda de que era un artista” y “iqué dulce y bondadosamente brillaban los ojos de aquel hombre [...]!”, en verdad es la señora Marta quien tiene esos pensamientos. En las respuestas correctas, dicen las autoras,

...los alumnos seleccionan correctamente enunciados narrados en tercera persona en los que aparece el punto de vista de la protagonista. [...] Los alumnos pueden responder correctamente porque conocen específicamente la técnica del DIL [discurso indirecto libre] o porque las marcas enunciativas del DIL en este relato son muy claras y el recurso se repite en varias partes del texto (ibíd:: г2). 
Otro alumno, en cambio, en lugar de transcribir un fragmento en estilo indirecto libre, optó por un copiar un enunciado en el que el narrador explicita un pensamiento de la protagonista, es decir, prefirió un pasaje en el que el narrador cuenta que el personaje piensa algo:

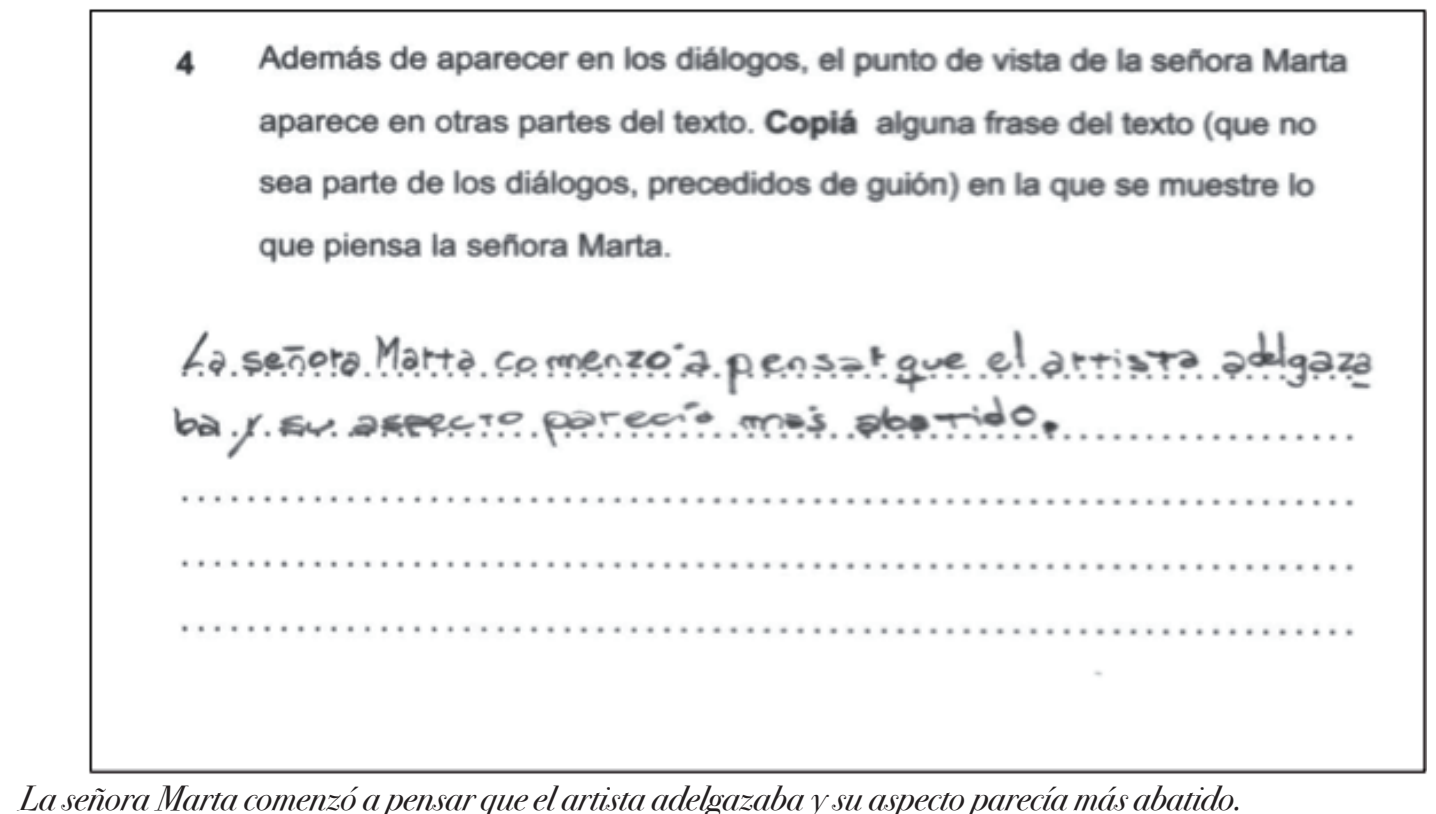

(ibíd.: г2)

El alumno cumplió con lo pedido: copió del cuento un enunciado, no incluido en un diálogo, en el que el narrador comunica un pensamiento del personaje. Posiblemente, para mayor seguridad, eligió un fragmento en el que el verbo "pensar" ("comenzó a pensar que") evidenciaba lo solicitado en la consigna: "que se muestre lo que piensa". Sin embargo, su respuesta ha sido considerada solo "parcialmente correcta" dado que, según las autoras del informe, no ha logrado descubrir la técnica narrativa utilizada por el narrador:

En este ejemplo, aunque el alumno entiende que se le pregunta por el personaje de la Sra. Marta, no ha podido reconocer el recurso del discurso indirecto libre (DIL) y transcribe un fragmento en el que el narrador describe externamente, desde afuera, una suposición del personaje. Este tipo de respuesta indica escasa experiencia lectora en esta clase de relato y en sus recursos (Ministerio de Educación de la Nación, 2008: г3).

La interpretación que las autoras hacen de su propia consigna pone en evidencia el ardid. En primer lugar, no hay en la respuesta del alumno elemento alguno que permita determinar que no reconoce la técnica del discurso indirecto libre. La actividad no lo requirió en ningún momento: la consigna solo pedía transcribir una frase, no perteneciente a un diálogo, que mostrara un pensamiento del personaje; no solicitaba necesariamente un fragmento en que el pensamiento del personaje se presentara en estilo indirecto libre. 
En segundo lugar, tampoco existe elemento alguno en la respuesta que permita deducir la escasa experiencia por parte del alumno en la lectura de relatos narrados con estilo indirecto libre. Lo único que puede deducirse de la respuesta transcripta es que el alumno logró reconocer una parte del texto en la que se comunicaba el pensamiento de un personaje que no se manifestaba a través de diálogos, es decir que realizó precisamente lo solicitado por la consigna.

En definitiva, pese al rigor con que se establecieron los contenidos, capacidades y criterios de evaluación, en ciertos casos, las consignas no parecen requerir una respuesta que "objetivamente" se desprenda de lo pedido. Por el contrario, las consignas están sujetas a la arbitrariedad del ardid, de modo que las respuestas consideradas como correctas (y especialmente las sentenciadas como incorrectas) dependen más de los ardides del destinador-evaluador que de la comprensión lectora del destinatario-alumno.

\section{La sobreinterpretación del destinatario-alumno}

Los ejemplos anteriores permiten deducir que, frente a ciertos ardides de las consignas, es posible que el destinatario tienda a cometer errores de sobreinterpretación, es decir, a equivocarse como consecuencia de creer haber encontrado un ardid que en verdad el destinador no ha introducido. A continuación presentamos un caso.

En un examen se solicitó a los alumnos la lectura de un artículo de opinión de José María Poirier-Lalanne; allí el autor busca sostener su posición, entre otros recursos, a través de diversas citas de autoridad: a lo largo del artículo recurre a opiniones vertidas por autores como Peter Handke, Pier Paolo Pasolini, Jean-Yves Calvez, etc. Con el fin de verificar si los alumnos comprenden el uso de la cita de autoridad como recurso argumentativo, el examen propone la siguiente consigna:

En este texto, ¿aparecen ideas que corresponden a un solo pensador, o más de uno? Fundamentá con ejemplos extraídos del texto:

Aparecen ideas que corresponden a :

Ejemplos

(Ministerio de Educación de la Nación, 2008: 24)

El siguiente es un ejemplo de respuesta considerada incorrecta: 


\section{En este texto, ¿aparecen ideas que corresponden a un solo}

pensador, o a más de uno?

Fundamentá con ejemplos extraídos del texto.

Aparecen ideas que corresponden a: $\sin \omega \cdot \mathrm{Ml}$.

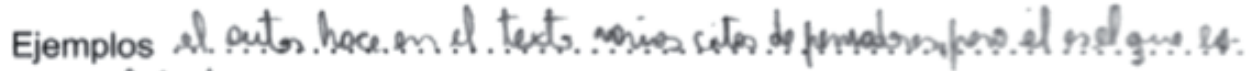

soils el texts.

Aparecen ideas que corresponden a: uno solo

Ejemplos: el autor hace en el texto varias citas de pensadores, pero él es el que escribe el texto.

(ibíd:: 28)

El criterio de corrección establece que una respuesta ha sido considerada incorrecta cuando "indica que el alumno piensa que aparece una sola voz en el texto" (ibíd::28). Y en relación con esta respuesta puntual se indica:

En estos ejemplos los alumnos no comprenden la pregunta y responden haciendo referencia a los lectores o al autor y no a las citas. Esto puede indicar que los alumnos no tienen experiencia en la lectura de textos argumentativos dialógicos, ricos en citas para apoyar o refutar argumentos (ibíd:: 29).

Sin embargo, creemos posible formular un análisis alternativo. Como hemos señalado, el género mismo de examen de comprensión lectora habilita la posibilidad de que la consigna se construya en torno a un ardid: la respuesta más evidente puede no ser la correcta; por este motivo, la consigna pone al destinatario "en guardia" y el lector corre el riesgo de sobreinterpretar por sospechar que detrás de toda consigna podría esconderse un ardid. Umberto Eco (I992) ha encontrado el modo de caracterizar el fenómeno de la sobreinterpretación a partir del vínculo entre la ambigüedad en el lenguaje, el exceso en la valoración de indicios y en lo que denomina "prácticas de interpretación sospechosa". Según Eco, "la sobrevaloración de los indicios nace a menudo de un exceso de asombro, o sea, de la propensión a considerar significativos los elementos más inmediatamente vistosos" (I992: IOO). Tomemos como ejemplo de “interpretación sospechosa" la respuesta a la consigna citada. 
La pregunta está construida en términos de disyunción: “¿aparecen ideas que corresponden a un solo pensador, o a más de uno?". No hay otra posibilidad: el destinatario tiene arriesgarse; es necesario optar por uno de los dos términos: uno solo o más de uno. Es aquí donde puede irrumpir el principio de sospecha acerca de un posible ardid que, en este caso, puede conducir al destinatario a vacilar en torno a la cuestión de la propiedad de las ideas: ¿A quién le pertenecen todas las ideas incluidas en un artículo? Si el autor del artículo es uno solo y opina exactamente como los pensadores a los que ese autor cita, ¿las ideas pertenecen al autor del artículo o también a los autores citados?

Por una parte, si se responde que aparecen ideas de un solo pensador, la respuesta es en parte correcta dado que el artículo pertenece a un solo autor, aunque es cierto que el autor incluye las opiniones de otros autores. Por otro lado, si se responde que aparecen ideas que corresponden a más de un pensador, la respuesta también es en parte correcta dado que el autor cita a otros autores para respaldar sus afirmaciones, aunque en verdad el artículo (y por lo tanto las ideas contenidas en él) pertenece a un solo autor, que es quien recoge esas ideas.

Frente a esta disyuntiva, el alumno optó por uno de los dos términos: señaló que las ideas pertenecen a un solo autor, pero aclaró ser consciente de que "el autor [...] hace varias citas de [otros] pensadores”. Sin embargo, los criterios de corrección establecidos a priori ya habían sentenciado su respuesta: el destinatario no debía indicar que aparecía una sola voz en el texto.

Veamos un segundo ejemplo. El texto proporcionado a los alumnos en uno de los exámenes del ONE 20O7, "Brazzaville, la capital africana con el nombre de un blanco", noticia publicada en 2006 por el diario Clarín, hace referencia a una polémica existente en aquel momento en Brazzaville, capital de la República del Congo, entre quienes estaban a favor y en contra de la construcción de un costoso mausoleo, un museo y una estatua en homenaje al explorador ítalo-francés Pierre Savorgnan de Brazza, fundador de aquella ciudad. En relación con el texto, una de las consignas que se propuso fue la siguiente:

Explicá en qué consisten cada uno de los puntos de vista que aparecen en el texto con respecto a las construcciones que se hicieron para homenajear a Brazza.

(Ministerio de Educación de la Nación, 2OIO: I8)

Según las autoras, las respuestas consideradas correctas fueron aquellas en que

los alumnos comprenden que hay una controversia con respecto a las construcciones que se han realizado en honor a Brazza: una que apoya el homenaje y otra que está en contra. Por otra parte pueden fundamentar cada una de estas posiciones con al menos un juicio... (ibíd.: 19). 
Es así como se ha considerado correcta la siguiente respuesta:

22 Explicá en qué consiste cada uno de los puntos de vista que aparecen en el texto con respecto a las construcciones que se hicieron para homenajear a Brazza.

El gabierno está a favor de la construcrión de Ia esta tua al argumentar que asi enriquecerán cultural mentca. sa pais los políticos de oposcición están en desacuerdo al argumentar que se podría gastar el diuero entre. tantas hecesidades.

El gobierno está a favor de la construcción de la estatua al argumentar que así enriquecerán culturalmente a su país. Los políticos de oposcición [oposición] están en desacuerdo al argumentar que se podría gastar el dinero entre tantas necesidades.

(ibid:: 2I)

Consideramos, sin embargo, que la lectura de la consigna en términos de ardid puede conducir a que el destinatario opte por explicar, literalmente, el punto de vista particular y específico de cada uno de los testimonios mencionados en la noticia. Un alumno, por ejemplo, respondió:

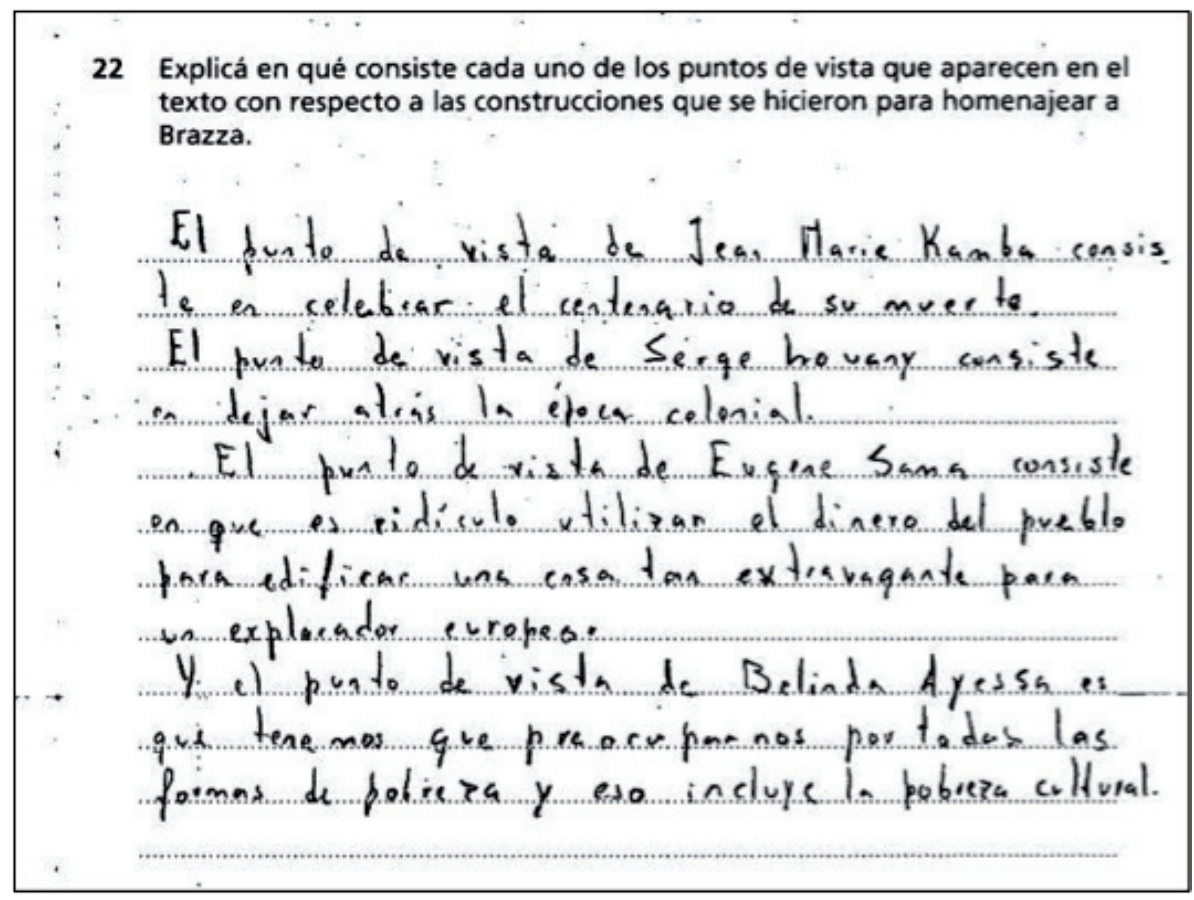

El punto de vista de Jean Marie Kamba consiste en celebrar el centenario de su muerte.

El punto de vista de Serge Louany consiste en dejar atrás la época colonial.

El punto de vista de Eugene Sama consiste en que es ridículo utilizar el dinero del pueblo para edificar una cosa tan 
extravagante para un explorador europeo.

Y el punto de vista de Belinda Ayessa es que tenemos que preocuparnos por todas las formas de pobreza y eso incluye la pobreza cultural.

(ibid:: 23)

La respuesta es considerada solo "parcialmente correcta":

...el alumno hace esfuerzos por registrar los distintos puntos de vista, pero al copiar casi textualmente fragmentos del texto, no puede expresar claramente el punto de vista de cada uno y lo que es más importante, no puede ponerlos en relación, compararlos, confrontarlos. Tampoco enuncia si son posturas a favor o en contra: simplemente las enumera sin dar cuenta de su comprensión (ibíd:: 23).

Es cierto que "el alumno hace esfuerzos por registrar los distintos puntos de vista" y que copia "casi textualmente fragmentos del texto" (esto último, por otra parte, no estaba prohibido por la consigna). Sin embargo, leída desde el punto de vista del destinatario que puede sospechar de la existencia de un ardid detrás de la expresión "cada uno de los puntos de vista" incluida en la consigna, es posible pensar que, ante la duda, convenía reseñar, al menos brevemente, todas y cada una de las opiniones que se mencionaban en el texto. Para el destinatario, no era tan importante poner en relación las opiniones ni confrontarlas; lo importante era que no faltara ninguna de las voces que el artículo registra. Solo así, desde una respuesta literal, era posible cumplir con la consigna de explicar en qué consiste cada uno de los puntos de vista sobre el tema.

Esta interpretación, que proponemos tentativamente, solo puede formularse desde fuera de los criterios de corrección establecidos para la lectura de las respuestas. Desde el punto de vista de estos criterios, tal interpretación está imposibilitada de formularse dado que taxativamente han establecido que solo debían indicarse dos puntos de vista: el que está a favor y el que está en contra. En otras palabras, las autoras nunca podrían haber interpretado que el alumno optó por desarrollar una respuesta literal que también es admisible (al menos en términos explicativos), porque los mismos criterios de corrección que han preestablecido les impiden formular tal análisis.

\section{Conclusiones}

El examen de comprensión lectora instrumentado en operativos de evaluación ha encontrado un formato relativamente estable que lo convierte en un género discursivo con una serie de rasgos característicos. Esos rasgos condicionan la lectura del destinatario: dado que la consigna puede contener un ardid destinado a dar por incorrecta la respuesta más evidente, el destinatario puede incurrir en una sobreinterpretación de la consigna. En este sentido, las equivocaciones no deberían considerarse simplemente como "errores de comprensión lectora"; deberían considerarse también como el producto de una sobreinterpretación generada por las características propias del género. 
La puesta en funcionamiento de categorías predefinidas que establecen criterios taxativos en la determinación de respuestas correctas e incorrectas presenta un doble problema. En primer lugar, en relación con la elaboración de las consignas, no existe "objetividad" ni "neutralidad" que garantice la existencia necesaria de una "obvia" respuesta correcta. El diseño de actividades depende, en ciertos casos, del arbitrio del destinador y no de un "va de suyo" lógico-deductivo como el que se pretende comunicar en los materiales; no siempre existen indicios que permitan establecer una relación "natural" de causa - consecuencia entre lo solicitado por la consigna y aquello que se prevé como la respuesta correcta. En segundo lugar, en lo relativo al análisis de las respuestas de alumnos, la aplicación rígida de criterios de corrección no permite interpretar los errores de los alumnos más que en términos negativos: "no comprendieron", "no observaron", "no hallaron", "no pudieron”. En efecto, las aserciones negativas son llamativamente abundantes en las interpretaciones de las autoras; el siguiente fragmento es un ejemplo típico de interpretación:

...el alumno hace esfuerzos por registrar los distintos puntos de vista, pero al copiar casi textualmente fragmentos del texto, no puede expresar claramente el punto de vista de cada uno y lo que es más importante, no puede ponerlos en relación, compararlos, confrontarlos. Tampoco enuncia si son posturas a favor o en contra: simplemente las enumera sin dar cuenta de su comprensión (Ministerio de Educación de la Nación, 2OIO: 23, cursivas nuestras).

Por el contrario, leídas desde fuera de los criterios preestablecidos por el operativo, en las respuestas a las consignas puede hallarse una lógica que responde a un modo de leer: en algunos casos, los alumnos parecen ajustarse a una respuesta literal; en otros, sobreinterpretan como consecuencia de la búsqueda de posibles ardides. Pero en cualquier caso, esos modos de resolver las actividades cuestionan tanto la existencia de un solo modo de pensar las respuestas a consignas de comprensión lectora como los límites entre lo acertado y lo erróneo cuando se trata de construir sentidos. 


\section{Bibliografía}

- Aguilar Hernández, L. (2006). Todo sea por la calidad. Tramar el cambio en educación. Valencia: Germania.

- Atorresi, A.; Centanino, I.; Bengochea, R.; Jurado, F.; Martínez, R. \& Pardo, C. (20o9). Aportes para la enseñanza de la Lectura. Segundo Estudio Regional Comparativo y Explicativo (SERCE). Santiago de Chile: OREALC/UNESCO Santiago - LLECE.

- Bajtín, M. (I982 [i978]). El problema de los géneros discursivos. Estética de la creación verbal. México: Siglo XXI, trad. Tatiana Bubnova.

- Calsamiglia Blancafort, H. y Tusón Valls, A. (1999). Las cosas del decir. Manual de análisis del discurso. Barcelona: Ariel.

- Ciapuscio, G. (r994). Tipos textuales. Buenos Aires: EUDEBA.

- Clemente Linuesa, M., y Domínguez Gutiérrez, A. (2003 [i999]). La enseñanza de la lectura. Enfoque psicolingüístico y sociocultural. Madrid: Pirámide.

- de Beaugrande, R., y Dressler, W. (1997 [1972]). Introducción a la lingüústica del texto. Barcelona: Ariel.

• Eco, U. (1992). Los límites de la interpretación. Barcelona: Lumen, trad. Helena Lozano.

- Leyva Barajas, Y. (2OII). Una reseña sobre la validez de constructo de pruebas referidas a criterio. Perfiles educativos, XXXIII(I3I), I3I-I54.

- Ministerio de Educación de la Nación (2008). Reflexiones para docentes de Lengua de la educación secundaria. Informe de preguntas abiertas. ONE 2005. Buenos Aires: DiNIECE.

- Ministerio de Educación de la Nación (20IO). Recomendaciones metodológicas para la enseñanza. Lengua. Educación Secundaria - ONE 2007/2008. Pruebas de $2^{\circ} / 3^{\circ}$ año y $5^{\circ} / 6^{\circ}$ año. Buenos Aires: DiNIECE.

- Ministerio de Educación de la Nación (2012). PISA. Lengua. Programa de Capacitación y Sensibilización. Módulo 1. Buenos Aires: DiNIECE.

- Miras, M.; Solé, I., y Castells, N. (200I). Evaluación en el área de lengua: pruebas escritas y opiniones de los profesores. Lectura y Vida, 21(2). Recuperado de http://www.lecturayvida. fahce.unlp.edu.ar/numeros/a2In2/2I_O2_Miras.pdf

- Parodi, G. (2005). Comprensión de textos escritos. Buenos Aires: EUDEBA 
- Silvestri, A. (1995). Discurso instruccional. Buenos Aires: EUDEBA.

- Solé, I. (200I). Evaluar lectura y escritura: algunas características de las prácticas de evaluación innovadoras. Lectura y Vida, 22(4). Recuperado de http://servicios2.abc.gov.ar/lainstitucion/sistemaeducativo/educacionartistica/destacado3congreso/descargas/bibliografia/ sole_evaluar_lectura_escritura.pdf

- van Dijk, T. \& Kintsch, W. (1983). Strategies of discourse comprehension. London: Academic Press.

-Viñao Frago, A. (2007). Modos de leer, maneras de pensar. Lecturas intensivas y extensivas. Revista Ethos educativo, 40, 47-70.

-Zayas, F. (2012). La competencia lectora según PISA. Reflexiones y orientaciones didácticas. Barcelona: GRAÓ. 